\title{
Problems associated with menstruation among medical students: a cross sectional study
}

\author{
A. Shantha ${ }^{1}$, Roselin V. ${ }^{2 *}$, Srisanthanakrishnan V. ${ }^{2}$
}

\begin{abstract}
${ }^{1}$ Department of Obstetrics and Gynecology, ${ }^{2}$ Department of Community Medicine, Sri Muthukumaran Medical College Hospital and Research Institute, Chennai, Tamil Nadu, India
\end{abstract}

Received: 18 January 2020

Accepted: 23 January 2020

\author{
*Correspondence: \\ Dr. Roselin V., \\ E-mail: drsanthanam.ssk@gmail.com
}

Copyright: ( ) the author(s), publisher and licensee Medip Academy. This is an open-access article distributed under the terms of the Creative Commons Attribution Non-Commercial License, which permits unrestricted non-commercial use, distribution, and reproduction in any medium, provided the original work is properly cited.

\begin{abstract}
Background: Medical students are at high risk for developing menstrual irregularities due to their lifestyle, food pattern and exercise habits. Also, majority of the menstrual disorders are preventable by changing better lifestyle, early diagnosis and treatment. Hence this study was conducted with the objective of addressing the menstrual disorders and associated problems among the medical students.

Methods: The cross-sectional study was conducted by the department of obstetrics and gynaecology, at Sri Muthukumaran Medical College Hospital and Research Institute, among the first, second- and third-year female students who are doing their MBBS course in the same institute, during the month of December 2019. A total of hundred students were included in the study. Data was collected using a proforma and analysis was done using Statistical Package for Social Sciences (SPSS) version 17.

Results: Menstrual cycle periodicity was irregular among $17 \%$ of participants. Dysmenorrhoea, mid cycle pain, heavy menstrual bleeding was noted among $27 \%, 19 \%$ and $11 \%$ respectively. Also $10 \%$ of students reported sickness absenteeism due to menstrual disorders.

Conclusions: Adolescent students should be educated on the importance of physical and mental health in terms of healthy food habits and regular physical exercise to overcome the menstrual disorders and to enjoy healthy reproductive period.
\end{abstract}

Keywords: Dysmenorrhoea, Medical students, Menstruation, Menstrual disorders

\section{INTRODUCTION}

Menstrual cycle is a physiological change that occurs in females. The process of menstruation is the flow of blood from the endometrial lining of uterus through the vagina. ${ }^{1}$ Girl's first menstruation refers to menarche and it is used as an indicator of maturity to assess the developmental status of a pubertal female. ${ }^{2,3}$

It generally occurs between the ages of 11 and 14 years in $95 \%$ of girls depending on race, ethnicity, socioeconomic and nutritional status. ${ }^{4}$ Menstrual cycle is irregular during the first year of menarche due to anovulatory cycles.
Weight, height, body fat and BMI are the factors which influence the regularity and duration of menstrual cycle.

Typically, a menstrual flow lasts 2-7 days with changing three to six pads per day suggests normal flow. The normal duration between two menstrual cycles ranges from 21 to 35 days. $^{5}$ Menstrual dysfunction occurs in majority of the adolescent girls and it may affect the life of adolescent and young adult women. ${ }^{6,7}$

Dysmenorrhea is one of the most common gynaecologic disorders among adolescent girls which may be associated with symptoms like headache, back pain, 
vomiting, nausea and diarrhoea. It is believed that the cause of the pain is excess production of prostaglandins (PG) in the endometrium during the ovulatory cycle8. It is the major cause of activity restriction and school absence in adolescent girls.

Medical students are at high risk for developing menstrual irregularities due to their lifestyle, food pattern and exercise habits. Dysmenorrhea and Premenstrual Syndrome are most commonly related to absence from class/college, limitation in social, academic, sports and daily activities. ${ }^{9,10}$ Medical students need to study harder and are vulnerable to stress, which may lead to dysfunction of hypothalamo-pituitary ovarian axis causing menstrual abnormalities. ${ }^{10}$

A number of medical conditions can also cause irregular cycles which can be diagnosed and treated at an early stage. However, this part of women's health is very crucial which needs to be concentrated. More than $90 \%$ of menstrual problems are preventable just by early detection and appropriate treatment. ${ }^{11}$ Hence this study was conducted with the objective of addressing the menstrual disorders and associated problems among the medical students.

\section{METHODS}

The cross-sectional study was conducted by the department of obstetrics and gynaecology, at Sri Muthukumaran Medical College Hospital and Research Institute, among the first, second- and third-year female students who are doing their MBBS course in the same institute, during the month of December 2019. Based on the literature12, considering the prevalence of irregular menstrual cycles among students as $40 \%$ with confidence of $95 \%$ and relative precision of $10 \%$, the sample size was calculated as ninety-three and it was rounded to hundred. Hence, a total of hundred students were included in the study. Students who were on treatment with hormonal pills were excluded from the study.

The principal investigator explained the purpose of the study to each participant and a written consent was obtained from the participants prior to the commencement of the study.

The participants were also informed that their participation was voluntary and that they could withdraw from the interview at any time without consequences.

Every effort was made, to be sure that all information collected from the participants, remain confidential. The study was conducted using a questionnaire, covering particulars related to clinical and treatment history related to their menstrual disorders. Data was entered in Microsoft excel and data analysis was done using Statistical Package for Social Sciences (SPSS) version 17.

\section{RESULTS}

In this study among medical students $57 \%$ of them were in the age group of $19-20$ years, $38 \%$ of the participants were below 18 years of age and $5 \%$ of the participants were above 20 years of age. Among the study participants, maximum of $78 \%$ of the participants attained menarche between the ages of 12-14 years whereas $16 \%$ of the participants attained menarche in the age of 11 and below while $6 \%$ of the participants attained menarche after 14 years of age. Regarding Body Mass Index (BMI) $5 \%$ of the students were underweight and $21 \%$ of the students were found to be overweight and $2 \%$ of the students were obese. Menstrual cycle periodicity was regular for $83 \%$ of the participants in this study. Among 100 students menstrual cycle duration was regular for $83 \%$ of the participants, it was short for $1 \%$ of the participant and prolonged for $2 \%$ of the participant (Table 1).

Table 1: Characteristics of the study participants.

\begin{tabular}{|ll|}
\hline Variables & Percentage \\
\hline Age group & 38 \\
\hline$\leq 18$ years & 57 \\
\hline $19-20$ years & 05 \\
\hline$>20$ years & \\
\hline Age at menarche & 16 \\
\hline$\leq 11$ years & 78 \\
\hline $12-14$ years & 06 \\
\hline$>14$ years & \\
\hline BMI & 05 \\
\hline Underweight & 72 \\
\hline Normal & 21 \\
\hline Over weight & 02 \\
\hline Obese & \\
\hline Periodicity of menstrual cycle & 83 \\
\hline Regular & 17 \\
\hline Irregular & \\
\hline Duration of menstrual cycle & 97 \\
\hline Normal & 01 \\
\hline Shortened & 02 \\
\hline Prolonged & \\
\hline
\end{tabular}

Associated with menstrual cycles $27 \%$ of the participants had dysmenorrhoea, $19 \%$ of the participants had mid cycle pain, $11 \%$ of the participants had heavy menstrual bleeding, $2 \%$ of the participants had mastalgia and $1 \%$ of the participants. Associated medical conditions like hypothyroidism, hyperthyroidism, PCOD, stress and premenstrual syndrome was noted among 4\%, 1\%, $8 \%, 5 \%$ and $4 \%$ of the participants respectively (Table 2 ).

Ultrasonography was done for $14 \%$ of the participants in this study for menstrual cycle irregularities. Treatment was taken by $15 \%$ of the participants in this study. Also, ten percentages of participants were missed their academics due to menstrual disorders (Table 3). 
Table 2: Proportion of participants with associated clinical conditions.

\begin{tabular}{|ll|}
\hline Variables & Percentage \\
\hline Associated Symptoms & \\
\hline Heavy menstrual bleeding & 11 \\
\hline Dysmenorrhoea & 27 \\
\hline Vomiting & 01 \\
\hline Mastalgia & 02 \\
\hline Mid cycle pain & 19 \\
\hline Associated conditions & \\
\hline Hypothyroidism & 04 \\
\hline Hyperthyroidism & 01 \\
\hline PCOD & 08 \\
\hline Stress & 05 \\
\hline Pre-menstrual syndrome & 04 \\
\hline
\end{tabular}

Table 3: Treatment aspects of the study participants.

\begin{tabular}{|ll|}
\hline Variables & Percentage \\
\hline USG done & \\
\hline Yes & 14 \\
\hline No & 86 \\
\hline Treatment taken & \\
\hline Yes & 15 \\
\hline No & 85 \\
\hline Sickness absenteeism & \\
\hline Yes & 10 \\
\hline No & 90 \\
\hline
\end{tabular}

\section{DISCUSSION}

The present study was conducted to assess the menstrual disorders and associated problems among the medical students. Among the study participants, maximum of $78 \%$ of the participants attained menarche between the ages of 12-14 years whereas $16 \%$ of the participants attained menarche in the age of 11 and below while $6 \%$ of the participants attained menarche after 14 years of age. Mean (SD) age of menarche was $13.1 \pm 0.8$ years. This finding is consistent with the reports of Begum et a, where they reported mean age as 13 years and Ikaraoha et al also reported a mean age at menarche of 13.89 years. ${ }^{13,14}$ The age of menarche is determined by number of factors such as, general health, genetic factors, socioeconomic and nutritional status. ${ }^{15}$

In this study, menstrual cycle periodicity was regular for $83 \%$ of the participants in this study. Among 100 students menstrual cycle duration was regular for $83 \%$ of the participants, it was short for $1 \%$ of the participant and prolonged for $2 \%$ of the participant. In the study conducted by Karout et al reported the most common menstrual disorders were irregular frequency of menstruation $(80.7 \%)$ and irregular duration of menstruation $(43.8 \%)$. $^{12}$
Problems with menstrual pattern may affect $75 \%$ of girls, and are the major cause of recurrent short-term school absenteeism in female adolescents. ${ }^{6,7}$ Menstrual irregularity and prolonged menstrual bleeding are the most common menstrual disorders in early adolescents. Prolonged menstrual bleeding usually occurs early after menarche due to anovulatory cycles. In anovulatory cycles, estrogen unopposed by progesterone produces an unstable endometrial lining that eventually breaks down, and vasoconstriction and myocardial contractility do not occur. ${ }^{16}$

In this study, $27 \%$ of the participants had dysmenorrhoea, $19 \%$ of the participants had mid cycle pain, $11 \%$ of the participants had heavy menstrual bleeding, $2 \%$ of the participants had mastalgia and $1 \%$ of the participants. Associated medical conditions like hypothyroidism, hyperthyroidism, PCOD, stress and pre-menstrual syndrome was noted among $4 \%, 1 \%, 8 \%, 5 \%$ and $4 \%$ of the participants respectively. Other studies conducted by Lee et al and Amita et al reported the prevalence of dysmenorrhoea as $67.7 \%$ and $73.8 \%$, respectively. ${ }^{17,18}$

In this study, mid cycle pain was reported by $19 \%$ of participants whereas Amita et al, that reported mid cycle pains in $63.29 \%$ of participants. ${ }^{18}$ Similarly, in the study conducted by Jerry et al showed $49 \%$ subjects were suffering from mid cycle pain. ${ }^{19}$

In the present study, ten percentages of participants were missed their academics due to menstrual disorders. Similarly conducted by Klein et al it was reported that $14 \%$ of adolescents aged 12-17 years missed school because of menstrual cramps and it was more common in subjects with severe dysmenorrhea. ${ }^{6}$ Similarly Sickness absenteeism is significantly more among dysmenorrhic girls as reported by Avasarala et al and Weissmen et al. $^{20,21}$

\section{CONCLUSION}

In the present study, dysmenorrhoea and irregular cycles are more common. Also, the burden of sickness absenteeism is rising. Hence all the students should be educated on the importance of physical and mental health in terms of healthy food habits and regular physical exercise. Studies in large scale are needed to assess the in depth of this issue so as to prepare and implement health programmes at schools and college levels, to address the adolescent population.

\section{ACKNOWLEDGMENTS}

Authors would like to thank all, who has guided us by extending their knowledge and experience right from the inception to the completion of the work. Also, authors would like to acknowledge all the staffs, for their support during the study period. Last but not least authors thankful to this study participants, without whom, this study would not have been possible. 
Funding: No funding sources

Conflict of interest: None declared

Ethical approval: The study was approved by the Institutional Ethics Committee

\section{REFERENCES}

1. Strassmann BI. The evolution of endometrial cycles and menstruation. Quarter Rev Biol. 1996;71(2):181220.

2. Blondell RD, Foster MB, Dave KC. Disorders of puberty. Am Family Phys. 1999;60(1):209-18.

3. Cameron N, Nagdee I. Menarcheal age in two generations of South African Indians. Ann Human Biol. 1996;23(2):113-9.

4. Tanner JM, Davies PS. Clinical longitudinal standards for height and height velocity for North American children. J Pediatr. 1985;107:317-29.

5. Hickey M, Balen A. Menstrual disorders in adolescence: Investigation and management Hum. Reprod. Update. 2003;9:493-504.

6. Klein JR, Litt IF. Epidemiology of adolescent dysmenorrhea. Pediatr. 1981;68:661-4.

7. Ziv A, Boulet JR, Slap GB. Utilization of physician offices by adolescents in the United States. Pediatr. 1999;104:35-42.

8. Durain D. Primary dysmenorrhea: assessment and management update. J Midwifery Womens Health. 2004;49:520-8.

9. Singh A, Kiran D, Singh H, Nel B, Singh P, Tiwari P. Prevalence and severity of dysmenorrohea: a problem related to menstruation among first and second year female medical students. Indian J Physiol Pharmacol. 2008;52(4):389-97.

10. Sood M, Devi A, Azlinawati, Daher AM, Razali S, Nawawi H, et al. Poor correlation of stress levels and menstrual patterns among medical students. J Asian Behavioural Studies. 2012;2(7):59-66.

11. Mohite RV, Mohite VR; Correlates of the menstrual problems among rural college students of Satara district. Al Ameen J Med Sci. 2013;6(3):213-8.

12. Karout N, Hawai SM, Altuwaijri S. Prevalence and pattern of menstrual disorders among Lebanese nursing students. EMHJ. 2012;18(4):346-52.
13. Begum J, Hossain AM, Nazneen SA. Menstrual pattern and common menstrual disorders among students in Dinajpur Medical College. Dinajpur Med Col J. 2009;2(2):37-43.

14. Ikaraoha CI, Mbadiwe IN, Igwe CU, Allagua DO, Mezie O, Iwo GT, et al. Menarchial age of secondary school girls in urban and rural areas of rivers state, Nigeria. Online J Health Allied Scs. 2005;4:2.

15. Chowdhury S, Shahabuddin AM, Seal AJ, Talukder KK, Hassan Q, Begum RA, et al. Nutritional status and age at menarche in a rural area of Bangladesh. Ann Human Biol. 2000;27(3):249-56.

16. Bayer SR, DeCherney AH. Clinical manifestations and treatment of dysfunctional uterine bleeding. JAMA. 1993;269:1823-8.

17. Lee LK, Chen PCY, Lee KK, Kaur J. Menstruation among adolescent girls in Malaysia: a cross-sectional school survey. Singapore Med J. 2006;47(10):874.

18. Singh A, Kiran D, Singh H, Nel B, Singh P, Tiwari P. Prevalence and severity of dysmenorrhea: a problem related to menstruation, among first and second year female medical students. Indian $\mathrm{J}$ Physiol Pharmacol. 2008;52(4):389-97.

19. Jerry R, Klein JR, Iris F, Litt IF. Epidemiology of adolescent dysmenorrhea. Pediatr. 1981;68:661-4.

20. Avasarala AK, Panchangam S. Dysmenorrhoea in different settings: are the rural and urban adolescent girls perceiving and managing the dysmenorrhoea problem differently? Indian $\mathbf{J}$ Community Med. 2008;33(4):246-9.

21. Weissmen AM, Hartz AJ, Hansen MD, Johnson SR. The natural history of primary dysmenorrhoea: A longitudinal study. BJOG. 2004;111:345-52.

Cite this article as: Shantha A, Roselin V, Srisanthanakrishnan V. Problems associated with menstruation among medical students: a cross sectional study. Int J Reprod Contracept Obstet Gynecol 2020;9:952-5. 